\title{
Uso das Tecnologias de Informação e Comunicação por Professores da Área da Saúde da Universidade Federal de São Paulo
}

\section{Use of Information and Communication Technologies by Teachers of the Health Area of the Universidade Federal de São Paulo}

PALAVRAS-CHAVE

- Tecnologia Educacional;

- Educação Superior;

- Ciência da Informação;

- Tecnologia da Informação;

- Docentes;

- Educação Médica.

\section{KEYWORDS}

- Educational Technology;

- Higher Education;

- Information Science;

- Information Technology;

- Faculty;

- Medical Education.

Teresa Avalos Pereira ${ }^{I}$ Kelsy Catherina Nema Areco ${ }^{I I}$ Rita Maria Lino Tarcia ${ }^{I}$ Daniel Sigulem ${ }^{I}$

\section{RESUMO}

Objetivo: Investigar o uso das Tecnologias de Informação e Comunicação (TIC) por professores da Unifesp. Métodos: Estudo observacional descritivo do tipo transversal, baseado em amostra aleatória simples composta por 191 respondentes. Estudou-se a associação do número total de 27 TIC com as variáveis idade, sexo, titulação, lecionar em dois ou mais cursos e participação em curso preparatório para docência no ensino superior. Resultados: A idade média foi de 49 anos, 60,7\% do sexo feminino, 72,8\% em nível de doutorado e 33,0\% lecionavam em dois ou mais cursos. Observou-se associação negativa entre quantidade de TIC e idade, e associação direta entre titulação e realização de curso para docência. Conclusão: A quantidade de instrumentos utilizados diminuiu 1,2 a cada dez anos, aumentou 1,8 com a participação do docente em curso preparatório e 1 a cada titulação obtida.

\begin{abstract}
Objective: To investigate the use of Information and Communication Technologies (ICT) by UNIFESP professors. Methods: Descriptive cross-sectional observational study based on simple random sample of 191 respondents. We studied the association of a total of 27 ICT to the age, sex, academic qualification, status of teaching in two or more courses and involvement in preparatory course for teaching in higher education. Results: The mean age was 49 years, $60.7 \%$ female, $72.8 \%$ at the doctoral level and 33.0\% teaching on two or more courses. We observed a negative association between the amount of ICT and age, and a direct association between academic qualification and having completed teacher training. Conclusion: The amount of instruments used fell by 1.2 every 10 years, and increased by 1.8 with the participation of professors in preparatory courses and by 1 for each academic title obtained.
\end{abstract}




\section{INTRODUÇÃO}

Os sistemas de informação e as redes de computadores estão desempenhando um papel primordial na criação de um ambiente cooperativo e é por meio desses instrumentos que se dará a comunicação. Como descreve Lévy¹, novas maneiras de pensar e conviver são elaboradas no mundo das telecomunicações e da informática, e o que vai agregar maior peso a essas tecnologias é a interação e a colaboração de cada uma delas.

No meio educacional, a tecnologia pode auxiliar os estudantes a adquirir competências necessárias para se tornarem tomadores de decisões e solucionadores de problemas, comunicadores e colaboradores criativos de ferramentas de produtividade, pessoas que buscam, analisam e avaliam a informação e que ofereçam contribuições à sociedade ${ }^{2}$.

A utilização de computadores na educação como recurso de ensino e aprendizagem teve início na década de 1970. Em 1971, foi discutido o uso de computadores no ensino de Física, em um seminário promovido pela Universidade Federal de São Carlos (UFSCar). Segundo Moraes ${ }^{3}$, a precursora no uso de informática na educação foi a UFRJ, vindo a UFRGS e a Unicamp em seguida. Uma iniciativa nacional só foi tomada, em 1981, no I Seminário Nacional de Informática na Educação, na Universidade de Brasília, estabelecendo uma posição sobre o uso de computador como instrumento auxiliar do processo de ensino-aprendizagem ${ }^{4}$.

O computador, como ferramenta de apoio ao processo de ensino e aprendizagem, em especial a internet, favorece o desenvolvimento de propostas interdisciplinares e cooperativas e estimula uma postura investigativa em relação ao conhecimento. A educação sofre modificações com a introdução de novas mídias nos processos educativos, e essas mudanças estão ocorrendo no método comunicacional docente, trazendo possibilidades de mediação multimidiática da informação ${ }^{5}$. No entanto, a preocupação com a qualificação docente é uma constante, pois, conforme Almeida e Moran ${ }^{6}$, se a escola precisa se modificar, também os cursos de formação de professores precisam mudar profunda e radicalmente nas atividades pedagógicas e no domínio das tecnologias, facilitando o acesso à informação e à pesquisa.

As TIC podem ser um instrumento de auxílio no processo educativo, não como substituto do professor, pois o conhecimento não provém de uma tecnologia, mas, sim, da soma de habilidades e competências que habilitam o docente a efetivamente educar. Para se adaptar à comunicação mediatizada do conhecimento, o professor precisa reconhecer a tecnologia como recurso de aprendizagem, ser um orientador e cooperador do aluno na construção do conhecimento, estar em sinto- nia com esse novo cenário, pois competência é a capacidade de mobilizar diversos recursos cognitivos para enfrentar um tipo de situação ${ }^{7}$.

Para Carlini ${ }^{8}$, introduzir tecnologias no ambiente acadêmico, porém, parece trazer aos professores de ensino superior, apegados à tradição oral-presencial de transmissão de conhecimentos, uma sensação de inadaptação e retrabalho, sem falar na necessidade de adequação contínua da atividade docente. Dessa forma, será preciso incorporar as TIC na formação docente, se fortalecer em termos qualitativos e, consequentemente, investir em processos de construção de autonomia dos professores para a atuação pedagógica apoiada em tecnologias educacionais.

Quanto às abordagens pedagógicas, Mizukami ${ }^{9}$ salienta que a "concepção tradicional" é aquela em que predomina o conceito educativo brasileiro desde o Império, o ensino é centrado no professor, e o aluno é o receptor passivo, a educação é caracterizada como transmissão de conhecimentos, e a avaliação visa à reprodução do conteúdo dado em sala de aula. Essa concepção, infelizmente, ainda é identificada mesmo quando associada à utilização das TIC. A importância da interação na educação já era defendida por Paulo Freire ${ }^{10}$, que criticava a educação bancária, de memorização mecânica de conteúdos. $\mathrm{O}$ autor se contrapõe a essa concepção e defende a educação humanista e problematizadora, pressupondo o diálogo de caráter reflexivo, a emersão das consciências, numa inserção crítica da realidade.

Repensando no âmbito escolar, é necessário que se reflita sobre a questão do uso e incorporação das tecnologias como recursos para a construção de práticas pedagógicas curriculares inovadoras e eficazes. Portanto, não é o uso de tecnologia que permite superar a concepção tradicional da educação, ainda reconhecida nas escolas, em que o professor está focado num processo engessado e estático, uma vez que ensinar e aprender exigem mais flexibilidade, menos conteúdos fixos e processos mais abertos de pesquisa e comunicação ${ }^{11}$.

Nesse contexto, começaram a surgir questões pedagógicas quanto à necessidade de introduzir o computador, as suas facilidades e formas de utilizá-lo na educação como um instrumento facilitador da aprendizagem. Conforme Belloni ${ }^{12}$, será preciso, no entanto, reavaliar teorias e reinventar estratégias. À universidade caberá investir na produção acadêmica, repensar modelos teóricos e metodológicos, integrando as novas tecnologias de modo eficiente e crítico.

Para dar suporte aos questionamentos sobre em que consiste a formação de professores e a necessidade de planejar e articular a formação continuada no que diz respeito a uma utilização efetiva e de qualidade das TIC na esfera pedagó- 
gica, temos trabalhos de pensadores e educadores como António Nóvoa e Angel Pérez Gómez ${ }^{13}$. Os autores projetam o conceito de profissional reflexivo, reflexão na e sobre a prática docente, revendo sua própria atuação e resgatando a experiência no processo de aprendizagem. Assim sendo, a formação de professores provoca um discurso em favor de uma reforma educacional profunda.

Uma avaliação sobre o uso e atitudes em face das tecnologias nas escolas da Europa revela que os estudantes têm maior frequência de utilização das TIC nas aulas quando ministradas por professor competente nas tecnologias, que tenha habilidades nas mídias sociais e capacidade de usar a internet com segurança e responsabilidade, bem como opiniões positivas sobre os recursos das TIC no ensino, que saiba enfrentar obstáculos e tenha alto acesso à infraestrutura de tecnologias na escola. Esses professores são definidos no inquérito como digitalmente confiantes e solidários ${ }^{14}$.

As atuais TIC provocam a necessidade de constante superação do saber, de forma que devemos buscar novos caminhos de fluência e abertura do conhecimento. Assim, Gabriel ${ }^{15}$ entende que duas habilidades são essenciais para os docentes atuarem nesse novo panorama. A primeira é assumir a responsabilidade pelo que realmente importa - o futuro dos estudantes; por isso, os instrumentos utilizados não devem ser a finalidade da educação, mas, sim, moldados para capacitar os alunos para a vida. A segunda é fazer o novo trabalho de novas maneiras - professores que colaboram entre si conseguem resultados melhores; sendo assim, é preciso usar o conteúdo para ensinar novas habilidades, o que requer novos modos de atuação.

O termo TIC, de acordo com o Handbook for Teachers, da Unesco ${ }^{16}$, é definido como um conjunto de tecnologias associadas com o processamento de informação, envio e recebimento de mensagens. Justificamos, portanto, este estudo com base na importância do papel do professor diante da utilização das TIC no ensino superior, acreditando ser fundamental para a motivação e a concretização dos processos de ensino e aprendizagem.

\section{MÉTODOS}

Foi realizado estudo observacional descritivo do tipo transversal sobre a utilização das TIC com uma amostra aleatória simples com 191 indivíduos, representativa da população de 1.510 professores de ensino superior da Unifesp (Campus São Paulo). As variáveis de interesse avaliadas foram: sexo, idade, titulação, tempo de docência no ensino superior e na Unifesp, participação em curso preparatório para docência e cursos em que lecionavam. Quanto ao procedimento de coleta de dados, foram utilizados questionários em papel, autoaplicáveis, entregues juntamente com a Carta de Apresentação e o Termo de Consentimento Livre e Esclarecido.

Utilizou-se o programa estatístico SPSS®) (Statistical Package for the Social Sciences), versão 20.0, para análise descritiva e inferencial dos dados. O nível de significância utilizado foi $\alpha=0,05$ para todos os testes realizados.

Os dados categóricos foram resumidos em frequências absolutas e relativas. Os dados numéricos foram descritos pelas médias, desvio-padrão, mínimo e máximo. Para testar a associação entre as variáveis numéricas, utilizou-se a correlação de Pearson quando as variáveis tinham distribuição próxima à normal. Para a comparação de médias entre dois grupos, utilizou-se o teste t-student nos casos em que a variável tinha distribuição normal nos dois grupos (teste paramétrico) ou seu equivalente não paramétrico Mann-Whitney. A igualdade de variâncias foi testada pelo teste de Levene.

O modelo de regressão linear múltipla foi usado para verificar quais variáveis estudadas teriam impacto na quantidade de ferramentas de TIC usadas pelos professores do ensino superior da Unifesp.

O projeto de pesquisa foi aprovado pelo Comitê de Ética em Pesquisa da Unifesp em 10 de fevereiro de 2012, sob o número 2136/11.

\section{RESULTADOS}

Dos 191 respondentes, identificamos que a idade média foi de $49 \pm 10$ anos, variando entre 27 e 81 anos.

No que se refere à distribuição por sexo na amostra, foi constituída de 60,7\% (116) de mulheres e 39,3\% (75) de homens.

Quanto à titulação acadêmica, 50,3\% são doutores, 22,5\% com pós-doutorado, 18,8\% são mestres e 8,4\% especialistas.

Os cursos de graduação da Unifesp - Campus São Paulo são: Medicina, Enfermagem, Fonoaudiologia, Ciências Biológicas - Modalidade Médica, Tecnologia de Informática em Saúde, Tecnologia em Radiologia, Tecnologia Oftálmica.

As TIC usadas por mais de $80 \%$ dos docentes são: computador, internet, pesquisa em Bases de Dados de Saúde, processador de texto, programa de apresentação, buscadores e e-mail (Gráfico 1). Essas TIC são, em geral, usadas rotineiramente.

A Tabela 1 apresenta a distribuição da quantidade de instrumentos de TIC na amostra total (27 tecnologias). Obtivemos a média de 12,1 e desvio-padrão de 4,0.

A quantidade de ferramentas de TIC utilizadas não depende do sexo. Homens e mulheres não diferem estatisticamente quanto à quantidade de ferramentas TIC que utilizam $(\mathrm{p}=0,412)$ (Tabela 2). 


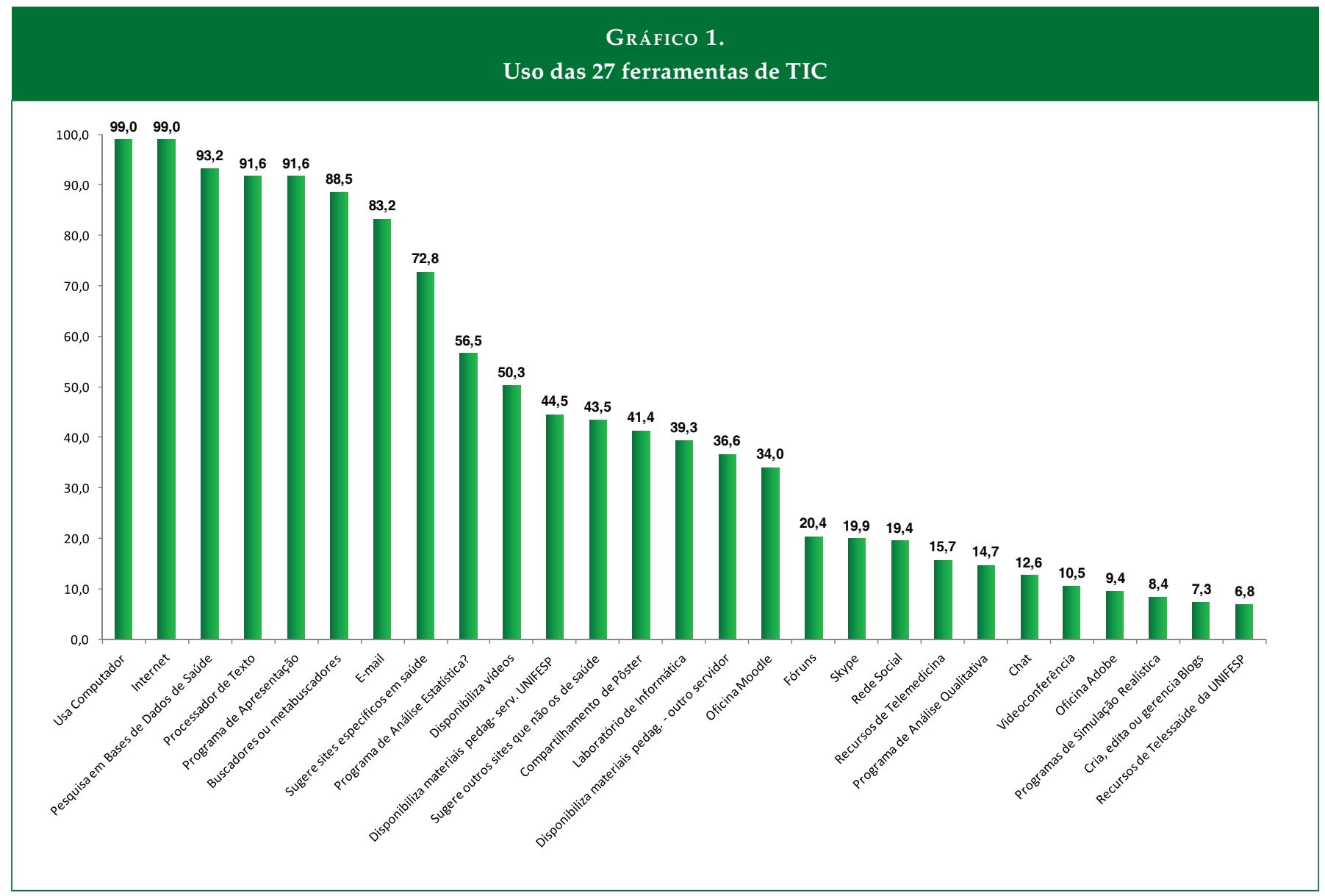

TABela 1.

Distribuição da quantidade de ferramentas de TIC na amostra total

$\begin{array}{cccccc} & \text { N } & \text { Média } & \text { Desvio-padrão } & \text { Mínimo } & \text { Máximo } \\ \text { Quantidade de ferramentas } & 191 & 12,1 & 4,0 & 0 & 23\end{array}$

\section{TABELA 2.}

Distribuição da quantidade de ferramentas de TIC utilizadas por sexo

\begin{tabular}{lcccccccc}
\multicolumn{1}{r}{ Sexo } & $\mathbf{N}$ & Média & Desvio-padrão & Mínimo & Máximo & Teste & p \\
Masculino & 75 & 11,8 & 4,8 & 0 & 4 & 23 & Teste-t & 0,412 \\
Feminino & 116 & 12,3 & 3,5 & 4 & 23 &
\end{tabular}

Obs.: variâncias diferentes ( $p=0,003)$

\section{TABELA 3.}

Distribuição da quantidade de ferramentas de TIC utilizadas por titulação

\begin{tabular}{|c|c|c|c|c|c|c|}
\hline Titulação & $\mathbf{N}$ & Média & Desvio-padrão & Mínimo & Máximo & $p$ \\
\hline Especialização & 16 & 11,1 & 4,39 & 5 & 20 & $\mathrm{p}=0,565$ \\
\hline Mestrado & 36 & 11,6 & 3,64 & 3 & 22 & \\
\hline Doutorado & 96 & 12,3 & 3,87 & 4 & 23 & \\
\hline Pós-Doutorado & 43 & 12,4 & 4,60 & 0 & 23 & \\
\hline
\end{tabular}


O coeficiente de correlação de Pearson entre a idade e a quantidade de ferramentas TIC foi $r=-0,211$. Isto significa que a quantidade de instrumentos de TIC usados decresce à medida que a idade aumenta (Gráfico 2).

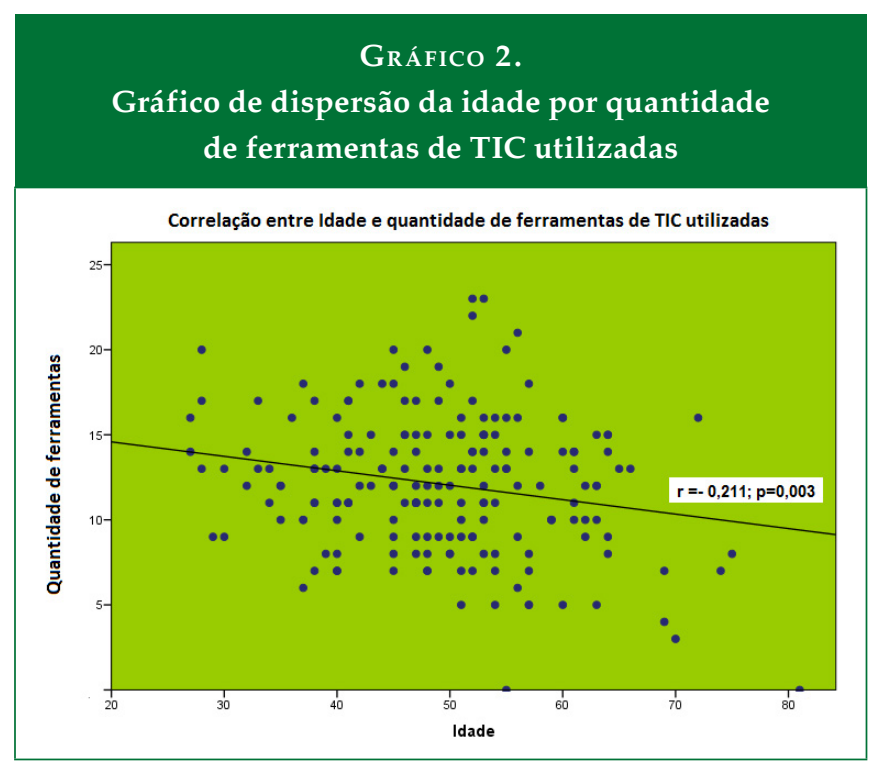

As médias da quantidade de ferramentas de TIC crescem com a titulação, variando de 11,1 para os que têm especialização a 12,4 para os que têm pós-doutorado. Esta diferença não foi estatisticamente significante na análise bivariada ( $\mathrm{p}=$ 0,565) (Tabela 3).

Os respondentes que participaram do curso de preparação para o exercício da docência no ensino superior têm média de quantidade de TIC mais alta do que os que não participa$\operatorname{ram}(\mathrm{p}=0,004)$ (Tabela 4$)$.

\begin{tabular}{|c|c|c|c|c|c|c|}
\hline \multicolumn{7}{|c|}{$\begin{array}{c}\text { TABELA } 4 . \\
\text { Distribuição da quantidade de ferramentas de } \\
\text { TIC utilizadas de acordo com a participação } \\
\text { em curso ou disciplina de preparação para o } \\
\text { exercício da docência no ensino superior }\end{array}$} \\
\hline $\begin{array}{c}\text { Participação } \\
\text { em curso }\end{array}$ & $\mathbf{N}$ & Média & $\begin{array}{l}\text { Desvio- } \\
\text { padrão }\end{array}$ & Mínimo & Máximo & $p$ \\
\hline Não & 102 & 11,3 & 3,8 & 0 & 20 & 0,004 \\
\hline Sim & 87 & 13,0 & 4,2 & 0 & 23 & \\
\hline
\end{tabular}

Obs.: variâncias iguais ( $p=0,764)$

A média da quantidade de ferramentas de TIC foi estatisticamente igual nos grupos de respondentes que atuavam em "1 curso" e "2 ou mais cursos" ( $p=0,187)$ (Tabela 5).
TABELA 5.

Distribuição da quantidade de ferramentas de TIC utilizadas pela quantidade de cursos de atuação

\begin{tabular}{lccccccc} 
& N & Média & $\begin{array}{c}\text { Desvio- } \\
\text { padrão }\end{array}$ & Mínimo & Máximo & Teste & p \\
\hline $\begin{array}{l}1 \text { curso } \\
2 \text { cursos } \\
\text { ou mais }\end{array}$ & 63 & 128,83 & 4,17 & 0 & 23 & Teste-t & 0,187 \\
\hline
\end{tabular}

Obs.: variâncias iguais $(p=0,170)$

Em adição, estudou-se a associação entre as variáveis idade, tempo de docência na Unifesp e tempo de docência em ensino superior, que se mostraram fortemente correlacionadas. Desta forma, a variável idade, utilizada na análise multivariada, representa também os tempos de docência (Tabela 6).

TABELA 6.
$\begin{aligned} & \text { Correlação entre as variáveis idade, tempo de docência } \\ & \text { na Unifesp e tempo de docência em ensino superior }\end{aligned}$
$\begin{aligned} & \text { Variáveis correlacionadas } \\ & \text { Coeficiente de } \\ & \text { correlação (r;p) }\end{aligned}$
$\begin{aligned} & \text { Idade e tempo de docência na Unifesp } \\ & \text { Idade e tempo de docência em ensino } \\ & \text { superior }\end{aligned}$
$\begin{aligned} & \text { Tempo de docência na Unifesp e tempo de } \\ & \text { docência em ensino superior }\end{aligned}$

Para identificar o conjunto de variáveis (sexo, idade, titulação, participação em curso preparatório para a docência e atuação em dois ou mais cursos) que poderiam estar associadas à quantidade de TIC utilizadas no ensino superior, primeiramente realizou-se análise bivariada, apresentada anteriormente, seguida da análise de regressão linear múltipla, que permite estudar a associação de cada variável na presença das demais.

Todas as variáveis de interesse foram incluídas no modelo multivariado, inclusive as que não se mostraram estatisticamente associadas à variável resposta (quantidade de TIC), como foi o caso da titulação.

O resultado da análise de regressão linear múltipla está apresentado na Tabela 7. Conclui-se que, do conjunto das variáveis estudadas, as que têm influência na quantidade de TIC utilizadas $(\mathrm{p}<0,05)$ são: idade, participação em curso preparatório para a docência e titulação. A quantidade de instrumentos de TIC utilizados diminui com o avanço da idade e aumenta com a participação do docente em curso preparatório para docência e com a titulação (Tabela 7). 


\begin{tabular}{|c|c|c|c|c|}
\hline \multicolumn{5}{|c|}{$\begin{array}{l}\text { TABELA } 7 . \\
\text { Resultados da análise de regressão linear múltipla } \\
\text { aplicada para estimar a quantidade de ferramentas } \\
\text { de TIC utilizadas na prática pedagógica }\end{array}$} \\
\hline $\begin{array}{l}\text { Variável independente } \\
\text { (fatores) }\end{array}$ & $\begin{array}{l}\text { Coeficientes } \\
\text { de regressão }\end{array}$ & $\begin{array}{l}\text { Erro } \\
\text { padrão }\end{array}$ & $\mathrm{t}$ & $p$ \\
\hline Intercepto & 14,437 & 1,484 & 9,727 & $<0,001$ \\
\hline Idade & $-0,123$ & 0,030 & $-4,135$ & $<0,001$ \\
\hline Participação em curso & 1,818 & 0,556 & 3,272 & 0,001 \\
\hline Titulação & 0,991 & 0,350 & 2,833 & 0,005 \\
\hline
\end{tabular}

\section{DISCUSSÃO}

Apesar de não coletarmos esses dados, vários profissionais alegaram dois obstáculos para o uso das TIC: remuneração insuficiente para fazer cursos e pouco tempo que lhes sobra para se capacitar. Sendo assim, a falta de formação específica docente na implantação de ferramentas tecnológicas ainda é apontada como um dos principais problemas na educação para a aquisição de competências técnicas e pedagógicas, para o compromisso aberto à inovação, motivação pessoal para esse domínio, hábito do trabalho colaborativo, conhecimento das potencialidades das TIC e sensibilidade da gestão das escolas.

A partir da compreensão das mudanças das funções dos educadores, dos avanços tecnológicos e do volume de novos recursos tecnológicos desenvolvidos, não era mais possível continuar educando da maneira como vinha acontecendo há anos. Sigulem ${ }^{17}$ declara que o problema vivenciado até hoje é que "as estruturas básicas da educação ainda são as mesmas, e a maior parte do ensino continua sendo oferecido em salas de aula, com grupos de estudantes que são orientados por um único professor" (p.47).

Ao mesmo tempo em que é necessário melhorar o acesso às novas tecnologias, Moran ${ }^{18}$ declara que precisamos pensar na escola como ambientes de aprendizagem inovadores e estimulantes, com aulas centradas em projetos, com atividades em espaços que não só a sala de aula, semipresenciais e online, sobretudo no ensino superior.

Na amostra que coletamos, encontramos sugestões de que deveria haver mudanças não só da escola, como também nas atitudes dos professores, com e pelas alterações das suas práticas. Para que haja domínio e integração das TIC na educação, é preciso programar ações efetivas para dotar os docentes de habilidades para melhor aproveitamento das tecnologias, a fim de obter resultados mais satisfatórios no processo de ensino e aprendizagem, assegurando que os saberes necessários à prática docente estejam sempre em (re)construção $0^{19}$.
A formação de professores para o uso efetivo das novas tecnologias digitais é importante, pois a velocidade das inovações tecnológicas é muito grande. Segundo Lévy ${ }^{20}$, os educadores precisam mudar suas atitudes, considerando que o conjunto de conhecimento individual é anulado diante do saber universal e que, com a ajuda das tecnologias, o processo de ensino e aprendizagem deve melhorar com a utilização da interdisciplinaridade e da inteligência coletiva reunida nas escolas.

Com a internet e a Web 2.0, Fava ${ }^{21}$ alerta que passamos da era da busca de informação para a social e participativa. Estudos mostram que os docentes ainda não estão preparados para ensinar nesta era de convergência, inteligência coletiva e cultura participativa. Por outro lado, acreditam que cursos que focam alfabetização digital deveriam ser incorporados aos currículos das escolas ${ }^{16}$.

Sobre alfabetização midiática e informacional, Wilson et al. ${ }^{22}$ sustentam que a produção de conteúdo e o uso das mídias podem promover uma pedagogia focada nos alunos, estimulando a investigação e o pensamento reflexivo por parte dos estudantes. A aprendizagem prática é um aspecto importante da assimilação de conhecimentos no século XXI, e os professores devem desempenhar um papel ativo nesse processo, fazendo com que os alunos desenvolvam competências para uma aprendizagem cada vez mais participativa.

Escolas para alunos do século XXI, líderes fortes, professores confiantes, abordagens inovadoras e metodologias mais participativas, alinhadas com estratégias de aprendizagem mais amplas, de acordo com Schleicher ${ }^{23}$, implicam novas competências e conhecimentos especializados, adquiridos e compartilhados de forma colaborativa, tanto horizontal quanto verticalmente.

Um recente estudo mostra que, nos países que contam com os melhores sistemas educacionais, a valorização da profissão docente é a chave para garantir a qualidade. Segundo Martins et al. ${ }^{24}$, as medidas que levam os sistemas escolares de melhor desempenho do mundo a alcançarem o topo são sintetizadas em quatro itens: selecionar os melhores professores, valorizar a profissão docente, não deixar aluno para trás e capacitar equipes de gestores. Inúmeros estudos já apontaram: a qualidade do professor é a característica que mais influencia a aprendizagem.

As TIC não modificam o que aprendemos, mas o modo como aprendemos. A mudança do paradigma educacional, portanto, é necessária perante os novos recursos didáticos e recentes tecnologias de informação. Os profissionais de hoje e de amanhã devem estar preparados para participar com sucesso e produtividade deste novo desafio ${ }^{17}$. 


\section{CONCLUSÕES}

O estudo permitiu conhecer as ferramentas de TIC utilizadas na prática acadêmica por professores e seus perfis demográficos e profissionais. Verificou-se que a maior parte deles não as utiliza ou não explora seus recursos educativos.

A quantidade de TIC utilizadas tem relação linear entre idade, titulação e participação em curso preparatório para a docência: diminui com a idade, aumenta com a participação do docente em curso preparatório para a docência no ensino superior e aumenta com a titulação.

Diante dos nossos resultados, uma postura perante os desafios da realidade exige desse profissional um compromisso com os conceitos de uma educação emancipadora, que possibilite a formação de pessoas autônomas, reflexivas e capazes de transformar a realidade em que estão inseridas. Em relação às práticas pedagógicas, os cursos de formação para professores são importantes na construção de conhecimento, levando-os a uma autorreflexão acerca de suas ações sobre o uso das tecnologias em sala de aula como alternativa complementar no ensino e aprendizagem de seus alunos.

Dessa forma, o docente com competência nas TIC será capaz de pesquisar, gerenciar, analisar e transformar a informação em conhecimento; trabalhar em conjunto; compartilhar o conhecimento com responsabilidade e ética; incorporar as tecnologias em seu desenvolvimento pessoal e profissional como parte integrante da sua realidade. Nesse cenário, o professor universitário necessita desenvolver a capacidade de aprender ao longo da vida, tendo em vista os rápidos avanços característicos desta sociedade.

A pesquisa nos faz refletir, ainda, que a universidade precisa se adaptar à evolução tecnológica atual, que exige alteração em políticas, currículos e práticas educativas. Nenhuma reforma educacional, pois, terá valor se a formação dos docentes não for priorizada.

\section{REFERÊNCIAS}

1. Lévy P. As Tecnologias da inteligência: o futuro do pensamento na era da informática. 13.ed. São Paulo: Editora $34 ; 2004$.

2. Organização das Nações Unidas para a Educação, a Ciência e a Cultura. Padrões de competência em TIC para professores: diretrizes de implementação. Versão 1.0 [on line]. Paris: UNESCO; c2009 [capturado 2010 Ago 18]. 17 p. Disponível em: http://unesdoc.unesco.org/ images/0015/001562/156209POR.pdf

3. Moraes MC. Informática educativa no Brasil: um pouco de história. Em Aberto [on line]. 1993 Jan-Mar [capturado 2010 Ago 18];12(57):17-26. Disponível em: http:/ / twingo.ucb.br/jspui/bitstream/10869/529/1/ Inform $\%$ C3\%A1tica $\% 20$ Educativa $\% 20$ no $\% 20$ Brasil $\% 20$ um $\% 20$ Pouco $\% 20$ de $\% 20 H i s t \% C 3 \%$ B3ria.pdf

4. Mendonça LG, Leite SQ. Uso de grupo de discussão no ensino regular como prática pedagógica além da sala de aula. Rev Perspect Cienc Tecnol.[on line] 2009 [capturado 2010 Ago 18];1(1):11-21. Disponível em: http://revistascientificas.ifrj.edu.br:8080/revista/index.php/revistapct/ article/view/22/12

5. Hack JR, Negri F. Escola e tecnologia: a capacitação docente como referencial para a mudança. Cienc Cogn. 2010;15(1):89-99.

6. Almeida ME, Moran JM, organizadores. Integração das tecnologias na educação: salto para o futuro [on line]. Brasília: Ministério da Educação; 2005 [capturado 2013 Out 10]. Disponível em: http://tvescola.mec.gov.br/images/ stories/publicacoes/salto_para_o_futuro/livro_salto_tecnologias.pdf

7. Perrenoud P. Dez novas competências para ensinar. Ramos PV, tradutora. Porto Alegre: Artes Médicas; 2000.

8. Carlini AL. O professor do ensino superior e a inclusão digital. In: Carlini AL. Scarpato M. Ensino superior: questões sobre a formação do professor. São Paulo: Avercamp; 2008. p. 83-94.

9. Mizukami MGN. Ensino: as abordagens do processo [on line]. Minas Gerais: UFVJM; 2010 [capturado 2013 Nov 12]. Disponível em: http://www.ufvjm.edu.br/site/educacaoemquimica / files /2010/10/ABORDAGENS-DO-PROCESSO.pdf

10. Freire P. Pedagogia do oprimido. 50aㅡ ed. Rio de Janeiro: Paz e Terra; 2011.

11. Moran JM, Masetto MT, Behrens MA. Novas tecnologias e mediação pedagógica. Campinas (SP): Papirus; 2012.

12. Belloni ML. Tecnologia e formação de professores: rumo a uma pedagogia pós-moderna? Educ Soc. 1998;19(65):143-62.

13. Pérez Gómez A. O pensamento prático do professor: a formação do professor como profissional reflexivo. In: Nóvoa A, organizadora. Os professores e sua formação. Lisboa: Publicações Dom Quixote; 1995, p. 93-114.

14. Survey of schools: ICT in Education [on line]. Belgium: European Union; 2013 [cited 2015 Jan 25]. Available from: file: / / C:/Users/Home/Downloads/SurveyofschoolsICTinEducation.pdf

15. Gabriel M. Educ@ar: a (r)evolução digital na educação.São Paulo: Saraiva; 2013.

16. United Nations Educational. Scientific and Cultural Organization. Information and communication technologies in schools: a handbook for teachers or how ICT can 
create new, open learning environments [on line]. Paris: UNESCO, Division of Higher Education; 2005 [cited 2013 Sep 13]. Available from: http://unesdoc.unesco.org/ images/0013/001390/139028e.pdf

17. Sigulem D. Um novo paradigma de aprendizado na prática médica da UNIFESP/EPM. São Paulo; 1997. Doutorado [Tese] - Universidade Federal de São Paulo. [capturado 9 dez. 2011]. Disponível em: https:/ / www.yumpu.com/pt/ document/view/12558525.

18. Moran JM. A educação que desejamos: novos desafios e como chegar lá. 5a ed. Campinas (SP): Papirus; 2012.

19. Pesquisa sobre o uso das tecnologias de informação e comunicação no Brasil: TIC Educação 2012 = Survey on the use of information and communication technologies in Brazil: ICT Education 2012 [on line]. DB Comunicação, tradutora. São Paulo: Comitê Gestor da Internet no Brasil; 2013 [capturado 2015 Abr 2]. Portuguese, English. Disponível em: http://www.cetic.br/media/docs/publicacoes/2/tic-educacao-2012.pdf

20. Lévy P. A inteligência coletiva: por uma antropologia do ciberespaço. São Paulo: Loyola; 2011.

21. Fava R. Educação 3.0. São Paulo: Saraiva; 2014.

22. Wilson C, Grizzle A, Tuazon R, Akyempong K, Cheung CK. Alfabetização midiática e informacional: currículo para formação de professores [on line]. Brasília: UNESCO; 2013 [capturado 2015 Abr 2]. Disponível em: http:/ / unesdoc.unesco.org/images/0022/002204/220418por.pdf

23. Schleicher A. Schools for 21st-Century learners: strong leaders, confident teachers, innovative approaches. In: International Summit on the Teaching Profession [on line];
2015 [capturado 2015 Abr 1]. Paris: OECD Publishing; 2015. Available from: http://istp2015.org/Documents/ ISTP2015_OECD-background-report.pdf

24. Martins AR, Santomauro B, Ratier R. Países com melhores sistemas de ensino podem inspirar soluções. Nova Esc [on line]. 2008 Out [capturado 2011 Dez 9];216:[cerca de 1 tela]. Disponível em: http:/ /revistaescola.abril.com.br/politicas-publicas/eles-podem-inspirar-busca-solucoes-423178.shtml

\section{CONTRIBUIÇÃO DOS AUTORES}

Teresa Avalos Pereira foi responsável pelo estudo em todas as suas fases - concepção e elaboração do projeto de pesquisa, aplicação do instrumento de coleta de dados, construção do banco de informações, revisão da literatura e redação final. Kelsy Catherina Nema Areco foi responsável pela análise, interpretação estatística e discussão dos dados. Rita Maria Lino Tarsia coorientou todo o projeto desde a concepção até a revisão do texto final. Daniel Sigulem foi orientador e revisor crítico do trabalho. Todos os autores aprovaram a versão final encaminhada para publicação.

\section{CONFLITO DE INTERESSES}

Os autores declaram não haver conflito de interesses.

\section{ENDEREÇO PARA CORRESPONDÊNCIA}

Teresa Avalos Pereira

Rua Botucatu, 862

Vila Clementino - São Paulo

CEP 04023-062 - SP

E-mail: te_avalos@hotmail.com 